\title{
Research on the Reform and Promotion Strategy of Mixed Teaching Mode in Colleges and Universities
}

\author{
Deng Min ${ }^{1,}$, Rao Xunjian ${ }^{1}$, Yang Dongqin ${ }^{2}$, Zhao $\mathrm{Ju}^{3}$ \\ ${ }^{1}$ Faculty of Geography Science and Tourism, Zhaotong University, Zhaotong, Yunnan, 657000, \\ China \\ ${ }^{2}$ School of Management, Zhaotong University, Zhaotong, Yunnan, 657000, China \\ ${ }^{3}$ Asset Management Service, Zhaotong University, Zhaotong, Yunnan, 657000, China
}

Keywords: Colleges and universities; Mixed teaching; Mode; Reform

Abstract: Nowadays, mixed teaching is the development trend of college teaching, however, there are not many colleges that promote the reform of mixed teaching mode at the school level. Based on the research of literature on the strategy of promoting the reform of mixed teaching mode at home and abroad, this paper constructs a strategy to promote the reform of mixed teaching mode in China from five aspects: top-level design, training system, quality monitoring and information feedback mechanism, incentive system and service system. Practice has proved that this strategy has created a mixed teaching mode reform atmosphere in colleges and universities, which has improved re-teaching ability, and improved students' learning enthusiasm and ability.

\section{Introduction}

With the rapid development of the Internet, modern online education in countries with higher levels of drama such as the United States, Britain, Australia, and Japan has developed rapidly. The mixed teaching reform has been successfully implemented in many foreign universities, forming a systematic mixed teaching reform management and practice model. Its excellent experience is worth learning from domestic universities. Although mixed teaching is a hot topic in current research, from the analysis of the results of domestic and international literature review, the research results of implementing mixed teaching at the institutional level are few. In foreign countries, Siemens pointed out in its research report "Welcome to Digital University: Remote, Mixed and Online Learning": "In our literature search, only one article systematically combed the implementation of mixed teaching at the institutional level."

\section{Overview of mixed teaching mode}

\subsection{Connotation of mixed teaching mode}

The mixed teaching mode is formed after the gradual development of new teaching modes such as MOOC class, micro-class, and flip class. It is a fusion of real classroom and online classroom. And as a teaching mode that integrates multimedia classrooms, micro-classrooms and other 
teaching modes through multiple channels such as offline and online. The technical support of mixed teaching is the development of information technology, while the theoretical support is to construct learning theory, emphasizing people-oriented, independent learning, knowledge building and learning interest. In short, mixed teaching is the epitome of today's teaching model and an important direction for college teaching reform.

\subsection{Characteristics of mixed teaching model}

The mixed teaching model has its own characteristics. Compared with the innovative teaching modes such as MOOC class, micro, and flip, it has the characteristics of balance, neither highlighting the dominant mode of teaching mode nor highlighting that a teaching mode is secondary. It recognizes the role and importance of each teaching model. On this basis, the "non-discrimination" teaching arrangements, the comprehensive use of different teaching models were implemented. The teaching method has achieved the teaching goal and improved the teaching efficiency. At the same time, the mixed teaching rationally treats the traditional teaching mode and applies it at an appropriate stage; as far as the mixed teaching mode itself is concerned, its characteristics are mainly interactive. This kind of interaction is not only the interaction between teachers and students, but also the interaction between teachers and students, life interaction and so on. Ways to achieve this kind of interaction include group teaching, classroom rotation, and so on.

\subsection{Principles of interactive teaching model}

University and college teaching is related to the cultivation of talents in the motherland. Therefore, the new teaching model should follow certain principles and serve the basic requirements of college education. Interactive teaching should follow three main principles: First, improve teaching efficiency. The ultimate goal of mixed teaching is to improve learning efficiency, that is, to improve the provability of knowledge in a certain period of time and to achieve the established teaching goals. Since mixed teaching is rich in content, thus If you don't put efficiency in a key position, it will easily make learning stagnate, and it will also make students lose their way. Second, it is necessary to highlight the importance of improving learning interest. One of the important purposes of the mixed teaching model is to mobilize the subjectivity and solve the problem of low enthusiasm of college students, so that students can learn independently and complete knowledge building. Therefore, stimulating learning interest is the responsibility of mixed teaching.

\section{The Challenges of the Mixed Teaching Mode in Colleges and Universities}

\subsection{The challenges to mixed teaching mode}

As shown in Figure 1, the detailed analysis is presented.

\subsubsection{Excessive weakening of teacher status}

Mixed teaching is the organic combination of real classroom and virtual classroom, independent learning and classroom teaching. Under such an educational model, interdisciplinary learning status has been emphasized to the greatest extent. In practice teaching, it could be observed that some teachers did not grasp the balance between betrayal and self-study, which led to part of the time students were self-study through the Internet, and the frustrating status was ignored. On the one hand, it reduces the student's goal, does not grasp the direction and focus of learning, on the other hand, it reduces the communication between students and teachers. After all, the network cannot 
communicate with students in thought and emotion. In the long run, it is easy to lead to the alienation between teachers and students, which have a negative impact on the psychological development of students.

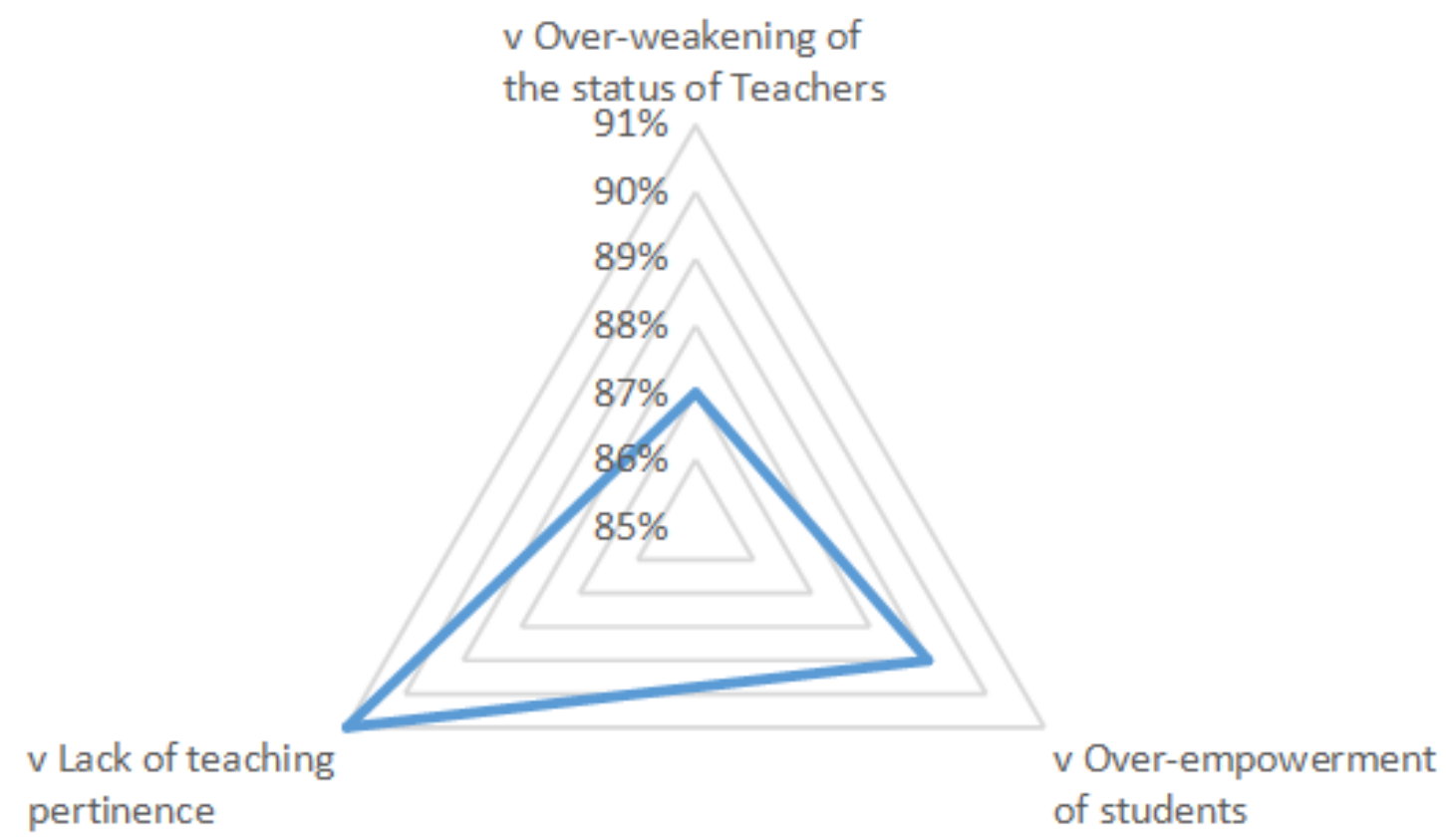

Figure 1. The Challenges of Mixed Teaching Model

\subsubsection{Excessive power of students}

The mixed teaching model emphasizes self-directed learning, but students are not allowed to make their own decisions. For example, some teachers let students learn online courses, but there is no corresponding supervision. Some students who do not have enough self-control have used the time to play online games or do things that are not related to learning. In this way, Deuteronomy has a negative impact on students' learning. Therefore, it should supervise Deuteronomy and improve the efficiency of students' self-directed learning.

\subsubsection{Lack of teaching pertinence}

Universities and colleges learning have established learning goals, including theoretical knowledge learning objectives and practical skills learning objectives. Mixed teaching focuses on the personalization of denuclearization, which could consider students of different levels and hobbies. However, in the face of numerous online resources and various learning methods, students cannot choose their own methods and content, nor can they arrange their own learning in strict accordance with the teaching progress. At present, mixed teaching is in a disorderly state, and denuclearization obviously lacks goals and plans. Therefore, the teaching should be further targeted and strengthened.

\subsection{External challenges to mixed teaching mode}

\subsubsection{Students are not adapt to the mixed teaching mode}

Chinese college students have been subjected to the traditional exam-oriented education before 
entering the university. They are accustomed to having teachers arrange their own studies, reading textbooks and doing exercises. Therefore, when these students enter the university, they will not be able to adapt to a mixed teaching model that emphasizes self-learning, online learning, and group learning. Some students don't know where to start learning, and some students have psychological conflicts. Therefore, teachers should pay attention to communication with students and eliminate discomfort when implementing mixed teaching methods.

\subsubsection{Changes should be made on school teachers}

College teachers have been accumulating experience in traditional teaching models. For some elder teachers, traditional teaching models and ideas are deeply rooted in their thinking. The mixed teaching mode is the fusion of a variety of new teaching modes, requiring teachers to re-recognize teaching and construct teaching methods and teaching systems from scratch. The transformation of the teaching model should first be the transformation of ideas. Only by recognizing the necessity of teaching reform and the advanced nature of the mixed teaching model, teachers can make up their minds to re-construct the teaching model, study the mixed teaching mode, and give full play to the advantages of the mixed teaching mode.

\subsubsection{Insufficient attention to the mixed teaching mode}

The mixed teaching model has not appeared for a long time, nor has it formed a mature teaching model, which is an important reason why the university leadership failed to vigorously promote the mixed teaching model. Currently, only university teachers are exploring a mixed teaching model. There is no unified organization and arrangement in the school, and there is no more help than traditional teaching. The promotion of the mixed teaching model requires the joint efforts of all parties, especially the support of school leaders. The lack of clear supportive attitudes of school leaders has had a negative impact on advancing the mixed teaching model.

\section{Reform strategies of mixed teaching model in colleges and universities}

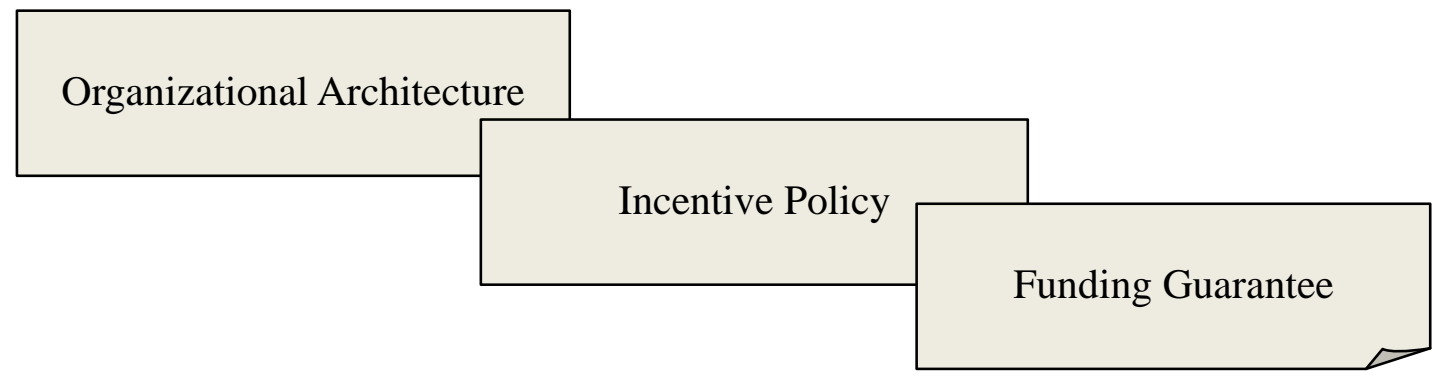

Figure 2. Reform Strategies of Mixed Teaching Model in Colleges and Universities

As a "first-class" project, the European reform of mixed teaching in higher vocational colleges needs to start from three aspects: teaching reform, professional teaching reform and curriculum design, from the three aspects of new administration, teachers, and students and teaching assistants, which is system engineering. It includes three aspects: theoretical system research, technical system participation and organizational program implementation. A comprehensive analysis and a comprehensive management dimension. As shown in figure 2.

\subsection{Reform of organizational architecture}

Universities and colleges should set up leadership groups to ensure the smooth implementation 
of mixed teaching reforms. The school principal is the team leader and the teaching vice president is the deputy leader. The team includes the heads of the Education Administration, Personnel, Production, Teaching and Research Center and the Center for Modern Educational Technology. The office is located in the administrative department, coordinates the division of responsibilities of relevant departments, and coordinates the effective operation of teaching reform.

\subsection{Reform of incentive policy}

Universities and colleges promulgated the "Management Measures for Mixed Teaching Reform", "Implementation Plan for Mixed Teaching Reform", "Cultivating Program for Mixed Teaching Reform", "Standard for Construction of Mixed Teaching Courses", "Testing Standards", "Reward Credit Standards", and Teacher Training", "Title Policy", "Guarantee Mechanism" and "Incentive Mechanism". Take active measures, etc., to strengthen the participation of teachers and students, and ensure the smooth progress of mixed teaching reform.

\subsection{Reform of funding guarantee}

Universities and colleges should establish special budgets guarantee for mixed teaching reform funds, and gives special funds in the construction of teaching platform, teaching resources, curriculum construction, etc., and gives a little incentive coefficient to increase the workload of teaching. Teachers who pass the project evaluation of mixed teaching mode reform courses and carry out mixed teaching reform are regarded as the recruitment conditions for Professional Title Evaluation and appointment.

\section{Conclusion}

In summary, the mixed teaching mode of colleges and universities is the result of continuous exploration of college education reform, and is an inevitable trend of science and technology and the development of the times. It should promote the hybrid teaching mode vigorously, and explore and innovate boldly, to achieve teaching objectives, stimulate learning interest as the guiding principle, rational layout, accurately locate curriculum resources, effectively improve teaching quality, and train qualified personnel for the society.

\section{Acknowledgement}

The Application of Blended Teaching Mode in Physiography under the Circumstances of Internet + (Ztjx201809)

\section{References}

[1] Lin Xueyan, Pan Jusu. Design and Implementation of Mixed Teaching Model Based on Flip Classroom [J]. China Vocational and Technical Education, 2016 (02).

[2] Wu Liyuan. Research on the Mixed Teaching Model Based on Peer Counseling [J]. Educational Review, 2016 (02).

[3] Yu Hongtao. A Case Study on the Evaluation of the Effectiveness of Mixed Teaching Reform in Institutions of Higher Learning: Taking Inner Mongolia University for Nationalities as an Example [J]. China's Audiovisual Education, 2017 (11).

[4] Chen Lifang, Wang Yunfan, Qiuhong. Mixed Teaching Reform Based on Innovative Thinking Training [J]. Journal of North China University of Technology (Social Science Edition), 2016 (05).

[5] Han Xibin, Wang Yuping, Zhang Railway, etc. Welcome to Digital University: On Distance, Mixing and Online Learning-Translation, Interpretation and Research [M]. Beijing: Tsinghua University Press, 2016:58. 